\title{
On the Potential Economic Costs of Cutting Carbon Dioxide Emissions in Portugal ${ }^{*}$
}

\author{
Alfredo Marvão Pereira \\ The College of William and Mary, CASEE, Universidade do Algarve \\ Rui Manuel Marvão Pereira \\ The College of William and Mary and Universidade do Algarve
}

\author{
College of William and Mary \\ Department of Economics \\ Working Paper Number 79 \\ Current Version: July 2010 \\ Previous Version: October 2008
}

\footnotetext{
* This paper is part of a research project financed by a grant from the Fundação de Ciência e Tecnologia do Ministério da Ciência e Tecnologia - Portugal, reference PTDC/ECO/72065/2006. We would like to thank participants of the 3rd Meetings of the Portuguese Economic Journal in June 2009 in Madeira, Portugal, the First Research Workshop of the CASEE in July 2009 in Faro, Portugal, as well as an anonymous referee for very helpful comments and suggestions.
} 
COLLEGE OF WILLIAM AND MARY

DEPARTMENT OF ECONOMICS

WORKING PAPER \# 79

July 2010

\title{
On the Potential Economic Costs of Cutting Carbon Dioxide Emissions in Portugal
}

\begin{abstract}
The objective of this paper is to estimate the impact of reducing carbon dioxide emissions from fossil fuel combustion activities on economic activity in Portugal. We find that energy consumption has a significant impact on macroeconomic activity. In fact, a one ton of oil equivalent permanent reduction in aggregate energy consumption reduces output in the long term by $€ 6,340$. More importantly, and since carbon dioxide emissions are linearly related to the amounts of fuel consumed, our results allow us to estimate the costs of reductions in carbon dioxide emissions. We estimate that a uniform standard for reducing carbon dioxide emissions from fossil fuel combustion activities would lead to a marginal abatement cost of €95.74 per ton of carbon dioxide. This is a first rough estimate of the potential economic costs of policies designed to reduce carbon dioxide emissions. At this level one may conclude that uniform, across the board reductions in carbon emissions would have a clear negative effect on economic activity. Hence, at the aggregate level there is clear evidence for a trade-off between economic performance and a reduction in carbon emissions. This opens the door to the investigation of the scope for policy to minimize the costs of environmental policy and regulation.
\end{abstract}

JEL Codes: C32, O13, Q43.

Keywords: carbon dioxide emissions, energy and the economy, environmental policy, vector autoregressive model

\author{
Alfredo Marvão Pereira \\ Department of Economics, The College of William and Mary, Williamsburg, USA \\ CASEE - Center for Advanced Studies in Economics and Econometrics, \\ Universidade do Algarve, Portugal \\ ampere@wm.edu \\ Rui Manuel Marvão Pereira \\ Thomas Jefferson Program in Public Policy, \\ College of William and Mary, Williamsburg, VA 23187, USA \\ CASEE - Center for Advanced Studies in Economics and Econometrics \\ Universidade do Algarve, Campus de Gambelas, 8005-139 Faro, Portugal \\ rmpereira@wm.edu
}




\section{On the Potential Economic Costs of Cutting Carbon Dioxide Emissions in Portugal}

\section{Introduction}

The objective of this paper is to estimate the economic impact of carbon dioxide emissions from fossil fuel combustion activities in Portugal in order to evaluate the economic costs of policies to reduce carbon dioxide emissions. This is a timely issue given the ongoing international efforts within the United Nations Framework Convention for Climate Change for the development of sustainable climate policies and European Union policies in the areas of climate change and energy. It is also a critical issue for ensuring the efficient and equitable participation of Portugal in these international efforts.

Environmental policies to reduce carbon dioxide emissions from fossil fuel combustion have traditionally focused on investment in research, development, and deployment of energy-efficient technologies, on restructuring the composition of fuel demand, and on reducing energy consumption. Naturally, the choice and design of such policies is bound to have an important impact on economic activity [see, for example, Manne and Richels (1992), Nordhaus (1993), Grubb et al. (1993), Gaskins and Weyant (1993), Zhang and Folmer (1998), Jorgenson (1998), Hue and Xu (2000) and Lasky (2003)].

Energy-efficiency improvements have the potential for bringing significant gains in productivity while reducing the consumption of fossil fuels and greenhouse gas emissions [see, for example, Barker, et al. (2007) and Scott et al. (2008)]. Nevertheless, their scope is rather limited. The development of energy-efficient technologies is more of a longterm prospect and more outside the scope of small or developing economies. In turn, 
international studies have often concluded that the fuel switching necessary to ensure deep cuts in emissions would increase direct energy system costs for households and firms as a result of a regulatory-induced shift to more expensive but cleaner fuels. Finally, reducing energy consumption seems undesirable as, if taken literally, would adversely affect economic performance. Ultimately, these considerations highlight the perceived trade-off between reducing carbon dioxide emissions from fossil fuel combustion activities and economic performance [see, for example, Chen et al. (2005)].

We start by considering the impact of final energy demand on aggregate output. Then, since carbon dioxide emissions are linearly related to the amounts of fuel consumed, our estimates of the impact of energy consumption on output allow us to estimate the marginal abatement costs for carbon dioxide emissions from fossil fuel combustion. This, in turn, allows us to gain an appreciation of the potential economic costs of policies directed at reducing emissions.

We obtain the impact of energy demand on output by estimating a four-equation vector auto-regressive (VAR) model relating output, employment, private investment and final energy demand. This allows us to highlight the dynamic feedback mechanisms among the different variables and captures both direct and indirect channels through which energy consumption affects output as suggested by a production technology mapping labor, capital and energy consumption to output. On one hand, as an input to production, energy directly affects output - a scale effect. On the other hand, energy may affect production indirectly through its impact on other inputs - a substitution effect.

Our methodological approach follows very much the recent trends in the literature. Recent advances in times-series analysis have stimulated research into the nature of the 
relationship between energy consumption and economic activity via the concept of Granger-causality [see, for example, Masih and Masih (1996), Cheng and Lai (1997), Asafu-Adjaye (2000), Stern (1993, 2000), and Oh and Lee (2004)]. Although the general results are mixed, the importance of the dynamic relationship between energy consumption and output is clear. In fact, bi-directional causality has served as the basis for generating forecasts of energy consumption based, at least partially, on the level of economic activity [see, for example, Crompton and Wu (2005), Francis et al. (2007), and Perobelli et al (2007)]. As a result, vector auto-regressive models have become a standard approach for forecasting energy consumption [see, for example, Energy Information Administration (2002)].

\section{Data and Preliminary Empirical Results}

This section describes the basic data set, presents the results of the unit root and cointegration tests, and addresses the issue of VAR model specification. All test results discussed in this section are available from the authors upon request.

\subsection{Data: sources and description}

We use annual data for aggregate output, employment, private investment, as well as final demand for energy from 1977 to 2003 . Since this sample period includes years before and after Portugal joined the European Union in 1986, the possibility of a structural break in 1986 is considered throughout the empirical analysis.

Economic data was obtained from Banco de Portugal (1997), Commission of the European Communities (1999) and Ministério das Finanças (2006). Data for final demand for energy was obtained from the Energy Balance Sheets published by Direcção 
Geral de Energia (Portuguese Department of Energy, DGE hereafter) and is measured in $10^{3}$ tons of oil equivalent (toe hereafter). Aggregate final demand for energy is defined as the sum of final demand for petroleum and its derivatives, coal, gas, biomass, and electricity. We consider the possibility of a structural break in 1998 consistent with the introduction of natural gas.

\subsection{Unit root and cointegration analysis}

This section considers the main results from the unit root and cointegration tests. We use the Augmented Dickey-Fuller (ADF) t-test to test the null hypothesis of a unit root in the different variables. The optimal lag structure is chosen using the BIC and deterministic components and 1986 and 1998 dummies on the deterministic components are included if appropriate.

We started by applying the ADF t-tests to output, employment, private investment and energy consumption, in log-levels, and consistently found that we cannot reject the null hypothesis of non-stationarity at the 5\% level of significance. We then tested for stationarity of all the variables in growth rates and consistently found that the null hypothesis of a unit root in the growth rates can be rejected for all variables at the 5\% significance level. We take this evidence as a strong indication that stationarity in growth rates is a good approximation for all variables.

We now test for cointegration among the variables in log-levels. Due to the size of our sample we use the Engle-Granger procedure, which is less vulnerable than the Johansen procedure to the small sample bias toward finding cointegration when it does not exist [see, for example, Gonzalo and Lee (1998) and Gonzalo and Pitarakis (1999)]. 
Following the standard Engle-Granger procedure, we perform ADF unit roots tests on the residuals of the linear relationships among the four variables. We consider four different cases each one considering a different endogenous variable in the cointegration relationship. This is because it is possible that one of the variables enters the cointegrating relationship with a statistically insignificant coefficient. In this case, a test that uses such a variable as the endogenous variable would not detect cointegration. Naturally, and since the cointegrating relationship if it exists is a linear combination of the four variables, if all of them enter in a statistically significant manner in this relationship, the ordering will not make a difference.

In these tests, the optimal lag structure was chosen using the BIC, and deterministic components and 1986 and 1998 dummies on the deterministic components are included if appropriate. Test results uniformly suggest that we fail to reject the null hypothesis of nocointegration. Accordingly, as far as these variables are concerned, there is no evidence for convergence in the long-term energy ratios of the Portuguese economy.

\subsection{VAR specifications and estimates}

We have determined that all of the variables in log-levels are stationary in growth rates and that they are not cointegrated. Accordingly, we follow the standard procedure in the literature and estimate VAR models in growth rates. The model specifications are determined using the BIC. In terms of the deterministic components the best specification includes a constant and a trend. Also, we find that the best specification includes structural breaks in 1986 and 1998.

It should be noted that the use of a trend in a model estimated in growth rates implies that some of the variables under consideration have a quadratic trend in levels. 
This reinforces the idea of absence of convergence in the long-term ratios of the Portuguese economy already suggested by the absence of evidence for cointegration.

\section{Identifying and Measuring the Effects of Energy Demand Shocks}

We use the impulse-response functions associated with the estimated VAR models to examine the effects of innovations in energy demand. This methodology allows dynamic feedbacks among the different variables to play a critical role, both in the identification of shocks in energy demand and in measuring the effects of such shocks.

\subsection{Identifying shocks in energy demand}

The key methodological issue in determining the effects of energy demand on economic performance is identifying shocks in energy demand that are truly exogenous, i.e., that are not contemporaneously correlated with shocks in the remaining variables. We have in mind shocks induced by the introduction of environmental regulation, from, for example, the policy instruments considered within the National Program for Climate Change for Portugal with the objective of reducing carbon dioxide emissions from fossil fuel combustion activities. In dealing with this issue, we draw from the standard approach in the monetary policy literature [see, for example, Christiano, Eichenbaum and Evans (1996, 1998), and Rudebusch (1998)].

The econometric counterpart to the idea of identifying shocks in energy demand that are truly exogenous is to consider a reaction function, which relates the rate of growth of energy demand to the variables in the relevant information set. In our case, the relevant information set is defined as including past but not current observations of the growth rates of output, employment and private investment and energy demand. The residuals 
from this reaction function reflect the unexpected component of the growth in energy demand and are uncorrelated with shocks in the other variables.

Our reaction function approach is equivalent, in the context of the Choleski decomposition, to assuming that shocks in energy demand, while affecting contemporaneously economic performance are not affected contemporaneously by such economic performance. This assumption is very reasonable from a conceptual standpoint. Indeed, conceptually, we would expect shocks in energy demand to be either contemporaneously affected by all other variables but not only some of them or to contemporaneously affect all the other variables but not only some of them. Furthermore, we would expect that economic performance does not contemporaneously affect environmental policies that influence energy demand. This leaves as the only reasonable identifying alternative our assumption that shocks in energy demand affect contemporaneously economic performance but the reverse is not true. This is our central assumption.

The reaction function for energy demand is reported in Table 1. This function relates the growth in the energy demand variables to the evolution of output, employment and private investment, with a one year lag, according to the selected VAR specification. We find that aggregate changes in energy demand are positively correlated with lagged changes in output and that the other effects are not statistically significant.

\subsection{The impulse-response functions}

We consider the impact of a one percentage point, one-time shock to the rates of growth of the different types of energy demand. We expect these shocks to have at least temporary effects on the growth rates of the other variables. However, even temporary 
effects on the growth rates of the other variables translate into long-term permanent level effects for these variables. The accumulated impulse-response functions as well as the corresponding $90 \%$ bands that characterize the likelihood shape are presented in Figure 1. We observe that the accumulated impulse response functions converge within a very short time period suggesting that most of the growth rate effects occur within the first few years after the shocks occur.

The error bands surrounding the point estimates for the accumulated impulse responses convey uncertainty around estimation and are computed via bootstrapping methods. In no case is an effect of zero within the estimated error bands. This is the case despite the fact that we consider $90 \%$ intervals while bands that correspond to a $68 \%$ posterior probability are the standard in the literature (Sims and Zha, 1999). Our choice widens the values that characterize the likelihood shape and only serves to reinforce and strengthen our results.

\subsection{Measuring the effects of innovations in energy demand variables}

We estimate the long-term elasticities of the different economic variables with respect to each type of energy demand. The long-term refers to the time horizon over which the growth effects of the innovations disappear, i.e., the accumulated impulse-response functions converge. The accumulated elasticities, therefore, represent the long-term accumulated percentage point changes in the different variables for one long-term accumulated percentage point change in energy demand once all the dynamic feedback effects have been considered. The estimated elasticities under the central assumption as well as the range across all the possible Choleski assumptions are reported in Table 2. 
In turn, the corresponding marginal products measure the changes - in thousands of euros in private investment and output and in the number of long-term permanent jobs for a one toe accumulated increase in final energy demand. We obtain these figures by multiplying the average ratios of private investment, employment and output to energy demand, for the last ten years, by the corresponding elasticities. The decision to consider the average of the past ten years is designed to reflect the relative scarcity of final demand for the various types of energy considered without letting these ratios be overly affected by business cycle variations. The estimated marginal products are reported in Table 3.

Our methodological approach captures the dynamic interaction between final energy demand and private investment, employment and output. These dynamic feedback mechanisms are reflected in a policy rule for the evolution of final energy demand as well as in technological and market interactions among private investment, employment and output and between these and energy demand. Within this framework, final energy demand affects economic performance and, at the same time, growth in output, employment and investment affects energy demand through the policy function. The results we now present represent the final outcome of this dynamic process and fully incorporate all of the dynamic feedbacks resulting from the initial exogenous innovation in energy demand variable.

\section{On the potential costs of Reductions in Carbon Dioxide Emissions}

\subsection{On the Economic Effects of Shocks in Energy Demand}

The empirical results suggest that, over the long-term, energy demand crowds in both private investment and employment. The elasticity of private investment with respect to 
aggregate energy demand is 2.34 , which corresponds to a long-term marginal product of $€ 3,550$ per toe of final energy demand. In turn, the elasticity of employment with respect to aggregate energy demand is 0.48 which suggests that, over the long term, 0.0083 permanent jobs are created for each additional toe of final energy demand (or 1 job per 120.5 toe). Clearly then, final demand for energy has a significant positive impact on output over the long-term with an estimated elasticity of output with respect to energy demand of 0.97 , which corresponds to a long-term marginal product of $€ 6,340$ per toe.

Our results for the impact of shocks to energy demand on employment and output suggest that energy demand has a positive influence on long-term labor productivity in the economy. As such, the long-term responsiveness of output is greater than the longterm responsiveness of employment. Specifically, in the long term the labor-output ratio in the economy responds to shocks to energy demand with an elasticity of 0.49 .

\subsection{On the Effects of Reductions in Carbon Dioxide Emissions}

This section seeks to explore the relationship between fuel consumption, carbon dioxide emissions and economic performance by estimating marginal abatement costs for carbon dioxide emissions resulting from reductions in fossil fuel consumption.

To obtain the carbon dioxide emission factor for aggregate final energy demand we consider carbon dioxide emissions from fossil fuel combustion activities and not those from industry, waste, forestry and land use change. As such, to compute the aggregate economy-wide emission factor we consider total energy consumption and total carbon dioxide emissions from energy consumption. The implied average aggregate emissions intensity for aggregate energy consumption in the economy between 2000 and 2003 is $3.31 \mathrm{t} \mathrm{CO}_{2}$ per toe. 
Marginal abatement costs for carbon dioxide emissions from the combustion of fossil fuels are presented in Table 4. These costs reflect the impact of carbon dioxide emissions from final energy demand on private investment, employment and output.

We estimate that uniform standards across all energy sources would generate aggregate marginal abatement costs of $€ 95.74$ per ton of carbon dioxide. Private investment would fall by $€ 53.55$; over the long term, 0.0025 permanent jobs would be lost for every ton of carbon dioxide abatement from uniform standards across the final demand for each type of energy ( 1 job for every 400 tons of $\mathrm{CO}_{2}$ ).

As a way of illustrating our results consider the estimate of the impact of the $11 \mathrm{Mt}$ reduction in carbon dioxide emissions from fossil fuel combustion activities necessary to comply with the Portuguese commitment under the European Union Burden Sharing Agreement and which is considered within the National Program for Climate Change in 2006 (Resolução do Conselho de Ministros n. 104/2006). Uniform standards across all final demand energy would reduce GDP by $€ 1.053$ billion, or $0.73 \%$.

\section{Concluding Remarks and Directions for Future Work}

The objective of this paper is to empirically estimate the impact of reductions in carbon dioxide emissions from fossil fuel combustion activities on economic performance in Portugal.

Empirical results suggest that shocks in energy demand have a significant impact on private investment, employment and output. A permanent one ton of oil equivalent decrease in energy demand decreases output in the long term by $€ 6,340$. 
This result allows us to estimate the costs of environmental policies designed to reduce carbon dioxide emissions from fossil fuel combustion activities because carbon dioxide emissions are linearly related to the fuel vector consumed. We estimate that a uniform reduction across each type of energy would lead to an aggregate marginal abatement cost of $€ 95.74$ per ton of carbon dioxide. This is a first rough estimate of the overall economic costs of policies designed to reduce carbon dioxide emissions. At this level one may conclude that uniform, across the board reductions in carbon emissions would have a clear negative effect on economic activity. Hence, at the aggregate level there is clear evidence for a trade-off between economic performance and a reduction in carbon emissions.

The results in this paper should be understood as the first step in the analysis of the economic impact of environmental policies in Portugal. They should be understood as close to an upper bound in the cost of regulation when reductions of carbon dioxide emissions are achieved through reductions in consumption and not efficiency gains in energy use or fuel switching. Indeed, the next natural step would be to focus on the issue of fuel switching. In this context, the exact identification of the marginal abatement costs for different fuels and the potential for fuel switching as a way out of the aggregate trade off between reducing carbon dioxide emissions and promoting robust economic performance would be the key questions. 


\section{References}

Asafu-Adjaye, J. (2000), "The relationship between energy consumption, energy prices and economic growth: time series evidence from Asian developing countries," Energy Economics, 22(6):615-625.

Banco de Portugal (1997), Séries Longas para a Economia Portuguesa, Lisboa: Banco de Portugal.

Barker, T., P. Ekins, and T. Foxon. (2007). 'Macroeconomic effects of efficiency policies for energy-intensive industries: The case of the UK Climate Change Agreements, 20002010," Energy Economics, 29:760-778.

Cheng, B.S. and Tin Wei Lai, (1997). "An investigation of co-integration and causality between energy consumption and economic activity in Taiwan," Energy Economics, 19(4):435-444.

Chen, W., Z. Wu, J. He, P. Gao and S. Xu. (2005). "Carbon emission control strategies for China: A comparative study with partial and general equilibrium versions of the China MARKAL model," Energy, 32(1):59-72.

Christiano, L., M. Eichenbaum, C. Evans, (1996)."The effects of monetary policy shocks: evidence from the flow of funds," Review of Economics and Statistics 78(1):16-34.

Christiano, L., M. Eichenbaum, C. Evans, (1998). "Monetary policy shocks: what have we learned and to what end?" NBER 6400.

Commission of the European Communities (1999), European Economy 69, Brussels: Commission of the European Communities.

Crompton, P. and Yanrui Wu. (2005). "Energy Consumption in China: past trends and future directions," Energy Economics, 27: 195-208.

Direccao Geral de Energia. (2008). Balancos Energeticos. http://www.dgge.pt/

Energy Information Administration, U.S. Department of Energy (2002). "Model Documentation Report: Macroeconomic Activity Module of the National Energy Modelling System," Office of Integrated Analysis and Forecasting.

Francis, B.M., L. Mosley and S. O. Iyare. (2007) "Energy Consumption and projected growth in selected Caribbean countries," Energy Economics, 29: 1224-1232.

Gaskins, D. W. Jr., and J. P. Weyant. (1993) "Model comparisons of the costs of reducing $\mathrm{CO}_{2}$ emissions," American Economic Review 83(2):318-23. 
Gonzalo, J. and T. Lee, (1998) "Pitfalls in testing for long run relationships," Journal of Econometrics 86: 129-54.

Gonzalo, J. and J-Y Pitarakis, (1999). Dimensionality Effect in Cointegration Analysis, in Festschrift in Honour of Clive Granger, edited by R. Engle and H. White: 212-229. Oxford University Press.

Grubb, M., J. Edmonds, et al. (1993). "The costs of limiting fossil-fuels CO2 emissions: a survey and analysis," Annual Review of Energy and the Environment 18: 397-478.

Hue, G. J. Y. And H.M. Xu. (2000). "Impact of mitigating $\mathrm{CO}_{2}$ emissions on Taiwan's economy: a fuzzy multi-objective programming approach," Environmental Economics and Policy Studies, 3: 335-345.

Jorgenson, D., (1998). Growth Volume 2: Energy, the Environment, and Economic Growth. The MIT Press, Cambridge, Massachusetts.

Lasky, M., (2003). "The Economic costs of reducing emissions of greenhouse gases: a survey of economic models," Congressional Budget Office, Macroeconomic Analysis Division, Washington D.C.

Manne, A. S. and R. G. Richels, (1992). Buying Greenhouse Gas Insurance: The Economic Costs of $\mathrm{CO}_{2}$ Emission Limits, MIT Press, Cambridge, Massachusetts.

Masih, A.M.M, and Masih, R., (1996). "Energy consumption, real income and temporal causality: results from a multi-country study based on cointegration and error-correction modelling techniques," Energy Economics, 18(3):165-183.

Ministério das Finanças (2006). The Portuguese Economy, Lisboa: DGEP.

Nordhaus, W., (1993). "Reflections on the economics of climate change," Journal of Economic Perspectives, 7(4):11-25.

Oh, Wankeun and Kihoon Lee, (2004). "Causal relationship between energy consumption and GDP revisited: the case of Korea 1970-1999," Energy Economics, 26: $51-59$.

Perobelli, F.S., R.S. Mattos, E.A. Haddad and M.P.N Silva. (2007) "An integrated econometric + input-output model for the Brazilian economy: an application to the energy sector." Ecomod2007: International Conference on Policy Modeling. Sao Paulo, Brazil, July 11-13, 2007.

Resolucao do Conselho de Ministros n. 104/2006.

http://www.dre.pt/pdf1sdip/2006/08/16200/60426056.PDF 
Rudebusch, G., (1998), "Do Measures of monetary policy in a VAR make sense?" International Economic Review 39: 907-31.

Scott, M.J., J. M. Roop, R. W. Schultz, D.M. Anderson and K.A. Cort. (2008). "The impact of DOE building technology energy efficiency programs on U.S. employment, income and investment," Energy Economics, 30 (2), 2283-2301

Sims, Christopher A. and Tao Zha. (1999). "Error bands for impulse responses." Econometrica. Vol. 67, no. 5. pp. 1113-1155.

Stern, D. I. (1993) "Energy and economic growth in the USA - A multivariate approach," Energy Economics, 15(2):137-150.

Stern, D. I. (2000), "A multivariate cointegration analysis of the role of energy in the US macroeconomy," Energy Economics, 22(2): 267-283.

Zhang, Z.X. and H. Folmer. (1998). "Economic modeling approaches to cost estimates for the control of carbon dioxide emissions," Energy Economics, 20: 101-120. 
Table 1 Reaction functions for Final Energy Demand

\begin{tabular}{||c|c|c|c|c|c|c|c||}
\hline & $\begin{array}{c}\text { Dummy } \\
\mathbf{1 9 8 6}\end{array}$ & $\begin{array}{c}\text { Dummy } \\
\mathbf{1 9 9 9}\end{array}$ & Constant & Trend & $\Delta \mathbf{y}(-\mathbf{1})$ & $\Delta \mathbf{l}(-\mathbf{1})$ & $\Delta \mathbf{p}(-\mathbf{1})$ \\
\hline \multirow{3}{*}{$\Delta$ Energy } & $\begin{array}{c}0.00960 \\
(0.55135)\end{array}$ & $\begin{array}{c}0.00673 \\
(0.44913)\end{array}$ & $\begin{array}{c}0.03018 \\
(1.98963)^{* *}\end{array}$ & $\begin{array}{c}-0.00636 \\
(-0.43495)\end{array}$ & $\begin{array}{c}0.55936 \\
(1.79319)^{* *}\end{array}$ & $\begin{array}{c}-0.06244 \\
(-0.26068)\end{array}$ & $\begin{array}{c}0.04271 \\
(0.56001)\end{array}$ \\
\hline
\end{tabular}

Note: t-statistics in parenthesis. **significant at $10 \%$ level; ** significant at $5 \%$ level.

Table 2: Long-term Accumulated Elasticities with Respect to Final Energy Demand

\begin{tabular}{|c|c|c|c|}
\hline & Private investment & Employment & Output \\
\hline $\begin{array}{r}\text { Central case } \\
\text { Range of variation }\end{array}$ & $\begin{array}{c}2.33517 \\
{[-0.69657 ; 2.33517]}\end{array}$ & $\begin{array}{c}0.48084 \\
{[0.11040 ; 0.48085]}\end{array}$ & $\begin{array}{c}0.97402 \\
{[0.12443 ; 0.97402]}\end{array}$ \\
\hline
\end{tabular}

Note: Central case refers to the central Choleski orthogonalization assumption . The range of variation refers to all possible values under the Choleski decomposition approach and should not be understood or interpreted as a confidence intervals.

Table 3: The Economic Impact of Final Energy Demand

\begin{tabular}{|c|c|c|c|c|c|c|}
\hline & \multicolumn{2}{|c|}{ Private Investment } & \multicolumn{2}{|c|}{ Employment } & \multicolumn{2}{|c|}{ Output } \\
\hline & Elasticity & Marginal Product & Elasticity & Jobs Created & Elasticity & Marginal Product \\
\hline Energy & 2.34 & 3.55 & 0.48 & 0.00827 & 0.97 & 6.34 \\
\hline
\end{tabular}

Note: Marginal products measure the long-term permanent effects in thousands of Euros of a permanent increase of one ton of oil equivalent in final energy demand. Cost per Ton of Carbon Dioxide is measured in Euros per year

Table 4: The Economic Impact of Reducing Carbon Dioxide Emissions from Fossil Fuel Combustion

\begin{tabular}{||c|c|c|c|c|c||}
\hline \hline \multirow{2}{*}{$\begin{array}{c}\text { Emission } \\
\text { Factor }\end{array}$} & $\begin{array}{c}\text { Marginal } \\
\text { Product }\end{array}$ & $\begin{array}{c}\text { Cost per Ton of } \\
\text { Carbon Dioxide }\end{array}$ & $\begin{array}{c}\text { Eobs lost for each ton of carbon } \\
\text { dioxide abatement }\end{array}$ & $\begin{array}{c}\text { Marginal } \\
\text { Product }\end{array}$ & $\begin{array}{c}\text { Cost per Ton of } \\
\text { Carbon Dioxide }\end{array}$ \\
\cline { 2 - 6 } \\
3.31 & 3.55 & 53.55 & 0.0025 & 6.34 & 95.74 \\
\hline
\end{tabular}

Note: Marginal products measure the long-term permanent effects in thousands of Euros of a permanent increase of one ton of oil equivalent in final energy demand. Cost per Ton of Carbon Dioxide is measured in Euros per year 
Figure 1:

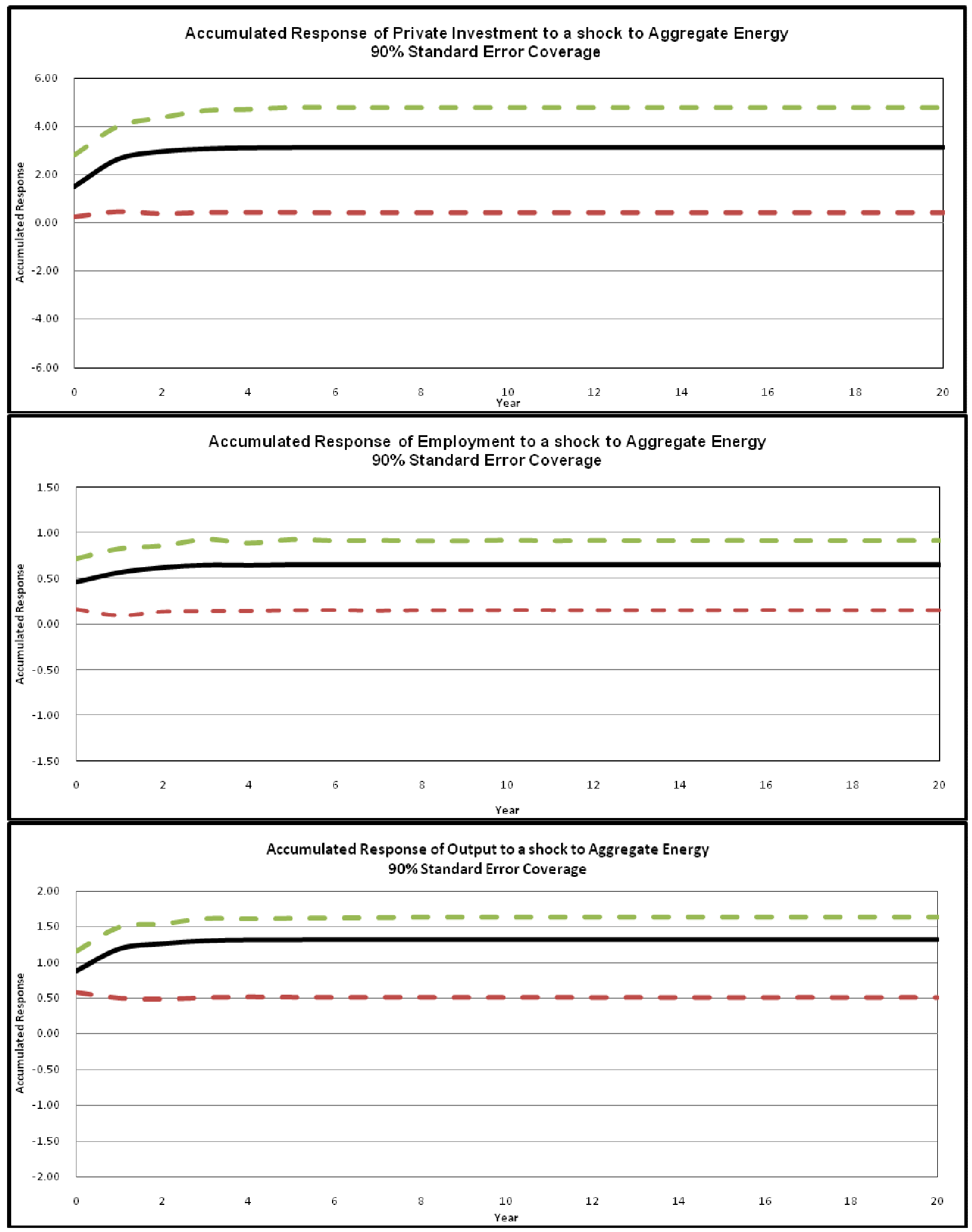

